\title{
Behavioral pattern of commercial public transport passengers in Lagos metropolis
}

\author{
Oluwaseyi Joseph Afolabi *, Adegbayi M. Hassan **, Luqman 0. Age *** \\ * Bells University of Technology, \\ KM 8, Benja Village, Idiroko Rd, Ota, Nigeria \\ Department of Management Technology \\ ** Olabisi Onabanjo University, \\ Ago-Iwoye, Ogun State, Nigeria \\ Department of Geography and Regional Planning \\ *** Lagos State Traffic Management Authority (LASTMA)
}

\section{open access (cc) dol}

\section{Article history:}

Received: April, 2017

1st Revision: April, 2017

Accepted: May, 2017

\section{DOI:}

10.14254/jsdtl.2017.2-1.4

\begin{abstract}
This study examined the travel behavior of commercial public transport passengers in Lagos State, Nigeria. The descriptive research survey was used in order to assess the opinions of the respondents using the questionnaire. A total of 84 samples were used as representative population, while two null hypotheses were formulated and tested using the Pearson Product Moment Correlation Coefficient at 0.05 level of significant. The results that were obtained indicated that a positive correlation exists between frequency of travel and commuters income in Lagos Metropolis and also that a positive correlation exists between frequency of travel and distance covered by commuters in Lagos Metropolis. Secondary data was also sourced to serve as complement to the primary data, thus allowing for a robust research. Descriptive statistical tools such as percentages were also adopted to present the socio-economic characteristics in the area. Findings showed that about $57 \%$ of sampled population are male, $62 \%$ are civil servants, $48 \%$ of respondents travel for business purposes. Also, that majority of the respondents (50\%) said that the commercial public transport is highly prone to accident, while about $64 \%$ of the respondents commute on daily basis. It was established that lack of transport infrastructure coupled with poor road maintenance were seen as the leading causes of inaccessibility of the area.
\end{abstract}

Corresponding author: Oluwaseyi Joseph Afolabi

E-mail: afolabiseyo@yahoo.com 


\section{Introduction}

Transport is the backbone of urban life. It is one of the factors which determines the form and socio-economic development of a city. Mobility and accessibility provided by the transport system have been playing a major role in shaping countries, influencing the location of social and economic activity, the form and size of cities, and the style and pace of life by facilitating trade, permitting access to people and resources, and enabling greater economies of scale worldwide and throughout history (Afolabi, 2008).

Transport is an important element in economic development and it affords the social and political interaction that most people take for granted (Afolabi, 2014). The provision of transport infrastructure has grown extensively across the globe through a range of networks of modes which have undergone technological improvements cutting across the motive power, the tracks as well as the means which serve as compartment for passengers and goods. It is also a key player in the transfer and distribution of goods from the input points through the manufacturing line to the customers (Agunloye, 2011). Perhaps, this led to the assertion by (Badejo, 2002), that there is no escape from transport since it is a key stone of civilization.

Travel behavior is the way people move in the public realm by all means of transport and for all purposes. Some of the activities people want to engage in are separated by space, which requires people to travel. The choices they make in order to travel are based on options, constraints, habits, and opportunities. For instance, how people travel to work (by car, bus, subway, or walk), the time they leave, and the duration and type of stops they make on the way are important aspects of travel behavior.

The frequent use of private cars in urban areas has a significant impact on the environment as well as on human health. Despite the fact that technical improvements, such as catalytic converts and fuel efficient engines, have decreased the pollution per vehicle, the environmental gains have been lost through the more extensive use of private cars (Parker, Manstead, and Stradlings, 1995). Other increasing problems concern auditory pollution, traffic accidents, excessive land use and the depletion of natural resources.

Generally, an attitude is defined as a psychological construct, composed of affective, cognitive and behavioral components, which may be used to describe human evaluative responses [6] (Fadare, and Ayantoyinbo, 2010).

Environmentally sound travel behavior seems to be one of the most difficult pro-environmental behaviors to promote in Nigeria (Handy, 2001). Approximately $50 \%$ of all journeys within urban areas, most of them less than five kilometers are made by car. Several reasons for the dominance of the private car have been brought up. The car is associated with time saving, comfort, freedom of movement and personal space. The car has also become essential in the life style of large groups in our society and thereby necessary for daily activities.

Innocent Ogwude (2011) investigated the acceptance and the perceived intrusion of various traffic restrictions. Based on the comparison of acceptance and intrusion scores, the author suggested that, in addition to selfish motives, there might also be a true concern for the environment.

However, in a scenario study by (Mumby, 1968): where the level of air pollution was varied, the results showed that increased pollution would reduce car driving. It might be that the private experience of environmental problems is an important determinant of pro-environmental behavior.

\section{Service as factor influencing travel behavior}

A service is an activity or series of activities of more or less intangible nature that normally, but not necessarily, take place in interactions between the customer and service employee and/ or physical resources or goods and/ or systems of the service provider, which are provided as solutions to customer problems (Odeleye, 2001). Mentioned the characteristics of services which include (Olawole, 2012):

a. Intangibility: the service cannot be touched or viewed, so it is difficult for clients to tell in advance what they will be getting.

b. Inseparability of production and consumption: the service is being produced at the same time that the client is receiving it (during an Electronic search, or a legal consultation). 
c. Perishable: unused capacity cannot be stored for future use. For example, spare seats on one airplane cannot be transferred to the next flight, and query-free times at the reference desk cannot be saved up until there is a busy period.

d. Heterogeneity (or variability): services involve people, and people are all different. There is a strong possibility that the same enquiry would be answered slightly differently by different people (or even by the same person at different times). It is important to minimize the differences in performance through training, standard-setting and quality assurance.

Oni (2004) travelers' mode choice is not only dependent on their socioeconomic backgrounds; the customers' perception of the mode also plays a significant role in affecting their choice. His study uses the ordered logit model with four ordered levels of perceptions on three mode-related aspects i.e. fare, convenience and frequency, and the result is then used as an input for the mode choice model.

Schwebel et al (2006) mentioned that service quality is very complex, that is why it is suitable to be a dimension and then explained through indicators to determine how good the service quality is through:

- Reliability, willingness to exactly give the type of service which has been promised to consumers or customers.

- Responsiveness, awareness or will to help consumer/ customer needs in an efficient way.

- Assurance, knowledge, politeness, self confidence from the server and also respect from the customers.

- Empathy, desire from server to approach and protect and the curiousness related with what the customers need and want

- Tangibility, performance from the employee and other physical facilities such as tool or equipment which support service.

\section{Factors that influence travel behavior}

The comfort level provided by Lagos city buses is a major element that leaves much to be desired, thereby reducing passenger perceived value and satisfaction with public bus transport services. This finding is in accordance with the findings of (Zeithaml \& Bitner, 2000) that comfort has the greatest impact on passenger satisfaction. With the exception of BRT buses, the operators/owners of other buses do not pay adequate attention to passenger comfort.

The basic public bus passenger requirements, such as comfortable seats and open windows for airflow, do not measure up to the standards. A majority of public buses are minibuses, which do not provide adequate legroom or even adequate ceiling heights for standing. Passenger discomfort worsens during rush-hour traffic when many passengers have to travel standing all the way in extremely crowded conditions. The results suggest that if comfort can be increased, Passengers satisfaction may lead to increased patronage in the use of public bus transport services in the city of Lagos. Comfort is an important consideration for Passengers of public bus transport and, as such, basic standards for comfort must be established and monitored to ensure that the Lagos bus operators adhere to them (Mumby, 1968).

\subsection{Accessibility}

Passengers perceived that bus routes, especially high-capacity bus routes, are not well spread in the city, which, according to them has reduced access to most destinations by bus. This requires them to walk relatively long distances before getting to the nearest bus stops to catch a bus. Added to this physical accessibility constraint is the time accessibility constraint, which manifests itself in the long waiting times for buses experienced by many Passengers due to the low frequency of bus services, mainly caused by vehicle traffic jams? This situation will not encourage people (especially private car owners) to use public bus transport for their daily travels. This is because bus riders do not wish to walk very far to their bus stops, and having arrived at the bus stop, they do not wish to wait for very long (Parker, Manstead, \& Stradlings, 1995). 


\subsection{Bus Stop Facilities}

Lagos commuters are not provided with adequate bus stop facilities. Inadequate facilities at bus stops were identified as another source of dissatisfaction of public bus passengers in the city. Very few bus stops (especially those in the city center area) offer appropriate physical structures and facilities for riders.

Many bus stops (especially those outside the seven high-capacity bus routes) do not provide protection (shelters) for passengers from sun, rain, dust, pollution, and other basic elements that have significant implications for health and safety.

Moreover, passengers have no place to sit for a long wait at bus stops, so there is no alternative but to remain standing. Unless these situations are corrected, expecting private car owners to use public bus transport will not materialize. The effects are that Lagos will continue to clog up, and this situation will be exacerbated in future as the city's population continues to grow. The opportunity costs of the traffic jams are incalculable.

\subsection{Bus Capacity Adequacy}

Passengers also perceived inadequacy of the capacity of public bus services to serve their needs as a factor that reduced their satisfaction. There is a problem of capacity in public bus transport services in the city of Lagos. The lack of availability of sufficient numbers of buses (especially highcapacity buses) is reflected in the long waiting lines and times, the frantic struggle to board a bus upon its arrival at most stops, and the lack of seating capacity in the buses. If a sufficient number of buses are provided for the Lagos commuters, enabling them to reach their destinations comfortably and on time, it will interest more people to use buses for their daily traveling need (Zumkeller, 2000).

\section{RESEARCH METHODOLOGY}

The Major Sources of Data Collection for the Study are Primary source and Secondary source.

The major primary source of data collected was through administering of questionnaires to road users (drivers and passengers) plying Oshodi routes. While secondary source comprises of textbook, journals, magazines, company, profile, newspaper publication and other relevant materials on the subject matter.

\subsection{Selection of Sample Size}

The techniques of sampling employed in the data collection are mainly random sampling. Direct questionnaire was provided to passengers on Travel Behavior of Commercial Public Transport Passengers in Lagos Metropolis. This is adopted with the view to reducing the degree of bias and sidedness of the respondent's opinion on the topic during the personal oral interview and distribution of the questionnaire. Secondly, to ensure that the views of all passengers are well and adequately represented, cluster sampling techniques was used to complement the random sampling. Due to the constraints of time, finances and other resources, the researcher could not reach out to the entire population that are legible to provide answers to the research questions of the study; this necessitated the use of a sample size of 84 commuters or road users which represents the unit of the population. 


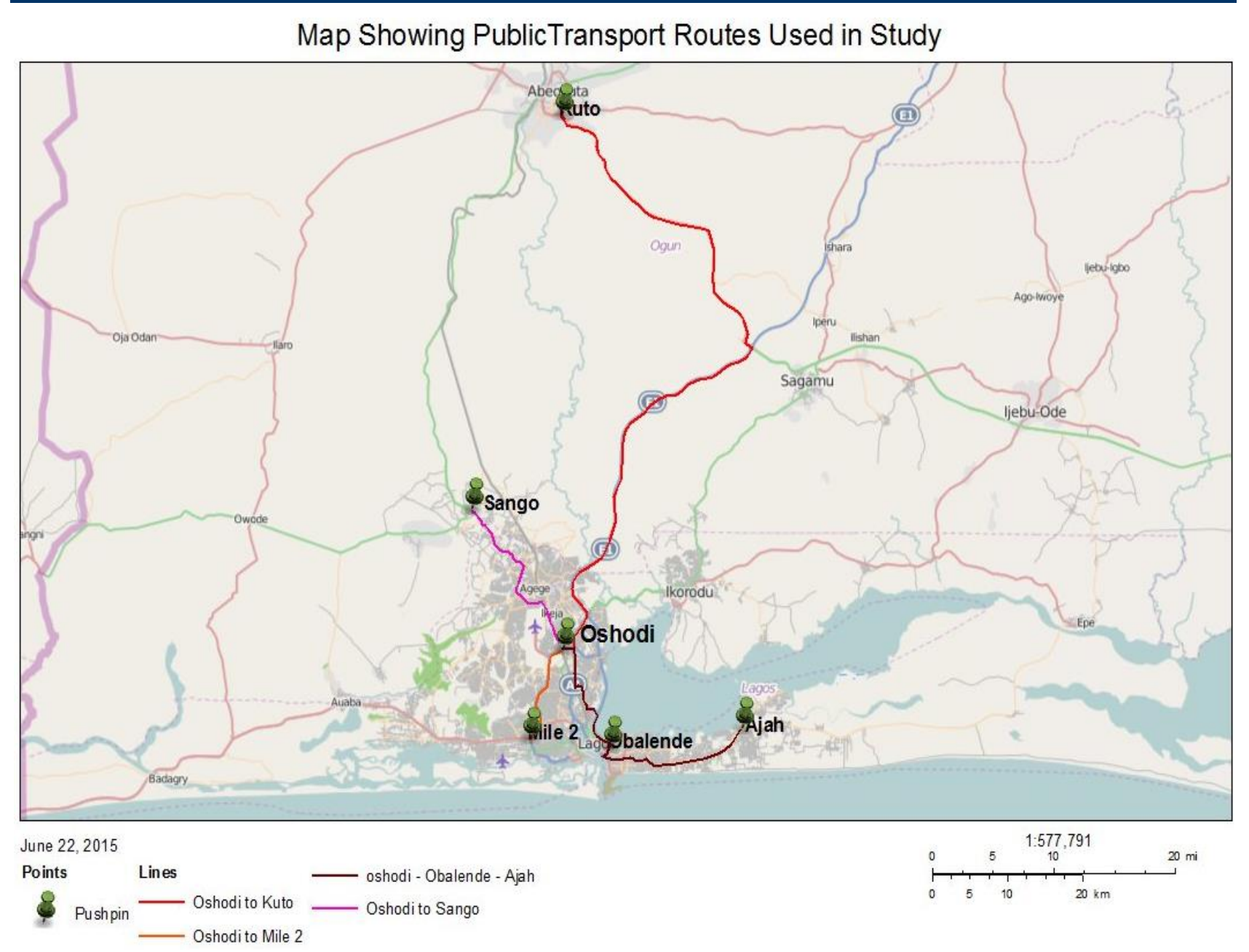

Fig. 1. Map showing public transport routes used in study

\subsection{Results and Discussion}

Out of the Hundred (100) questionnaires distributed to the respondents, Eighty-four (84) were effectively filled and returned which represent eighty-four percent (84\%) of the total respondents.

\subsubsection{Commuters' Behaviors}

\begin{tabular}{|l|c|c|c|}
\hline Table 1. Origins of Trips & Code & Frequency & Percentage (\%) \\
\hline \multicolumn{1}{|c|}{ Responses } & 5 & 12 & 14.29 \\
\hline Mushin & 4 & 20 & 23.81 \\
\hline Ilupeju & 3 & - & - \\
\hline Ojota & 2 & 10 & 11.90 \\
\hline Ketu & 1 & 42 & 50 \\
\hline Others & & $\mathbf{8 4}$ & $\mathbf{1 0 0}$ \\
\hline Total & & & \\
\hline
\end{tabular}

Source: field Survey, 2016.

Table 1 result shows that 42 respondents representing 50\% are coming from other places, 20 respondents representing $23.81 \%$ are coming from Ilupeju, while 10 respondents are coming from Ketu representing $11.90 \%$ and 12 respondent representing $14.29 \%$ are coming from Mushin. 


\begin{tabular}{|c|c|c|c|}
\hline Responses & Code & Frequency & Percentage (\%) \\
\hline Mile 2 & 5 & 19 & 22.6 \\
\hline Ajah & 4 & 20 & 23.8 \\
\hline Sango & 3 & 15 & 17.9 \\
\hline Obalende & 2 & 17 & 20.2 \\
\hline Abeokuta & 1 & 13 & 15.5 \\
\hline Total & & 84 & 100 \\
\hline
\end{tabular}

Source: field Survey, 2016.

Table 2 results shows that 19 respondents representing 22.6\% are dropping off at Mile 2, 20 respondents representing 23.8\% are coming down at Ajah while 15 respondents representing 17.9\% are heading towards Sango. $17 \%$ persons representing $20.2 \%$ are heading towards Obalende and 13 respondent representing $15.5 \%$ are embarking on journey to Abeokuta.

Table 3. Purposes of Commuting
\begin{tabular}{|l|c|c|c|}
\hline Responses & Code & Frequency & Percentage (\%) \\
\hline Education & 5 & 24 & 28 \\
\hline Social Activities & 4 & 14 & 17 \\
\hline Tourism/Recreation & 3 & - & - \\
\hline Business & 2 & 40 & 48 \\
\hline Others & 1 & 6 & $\mathbf{1 0 0}$ \\
\hline Total & & $\mathbf{8 4}$ & \\
\hline
\end{tabular}

Source: field Survey, 2016.

Table 3 results indicate that 24 respondents representing $28 \%$ are commuting for education, 40 respondents representing $48 \%$ are commuting for business, 14 respondents representing $17 \%$ are commuting for social activities while 6 respondent representing $7 \%$ are commuting for other purposes.

\section{Means of Commuting}

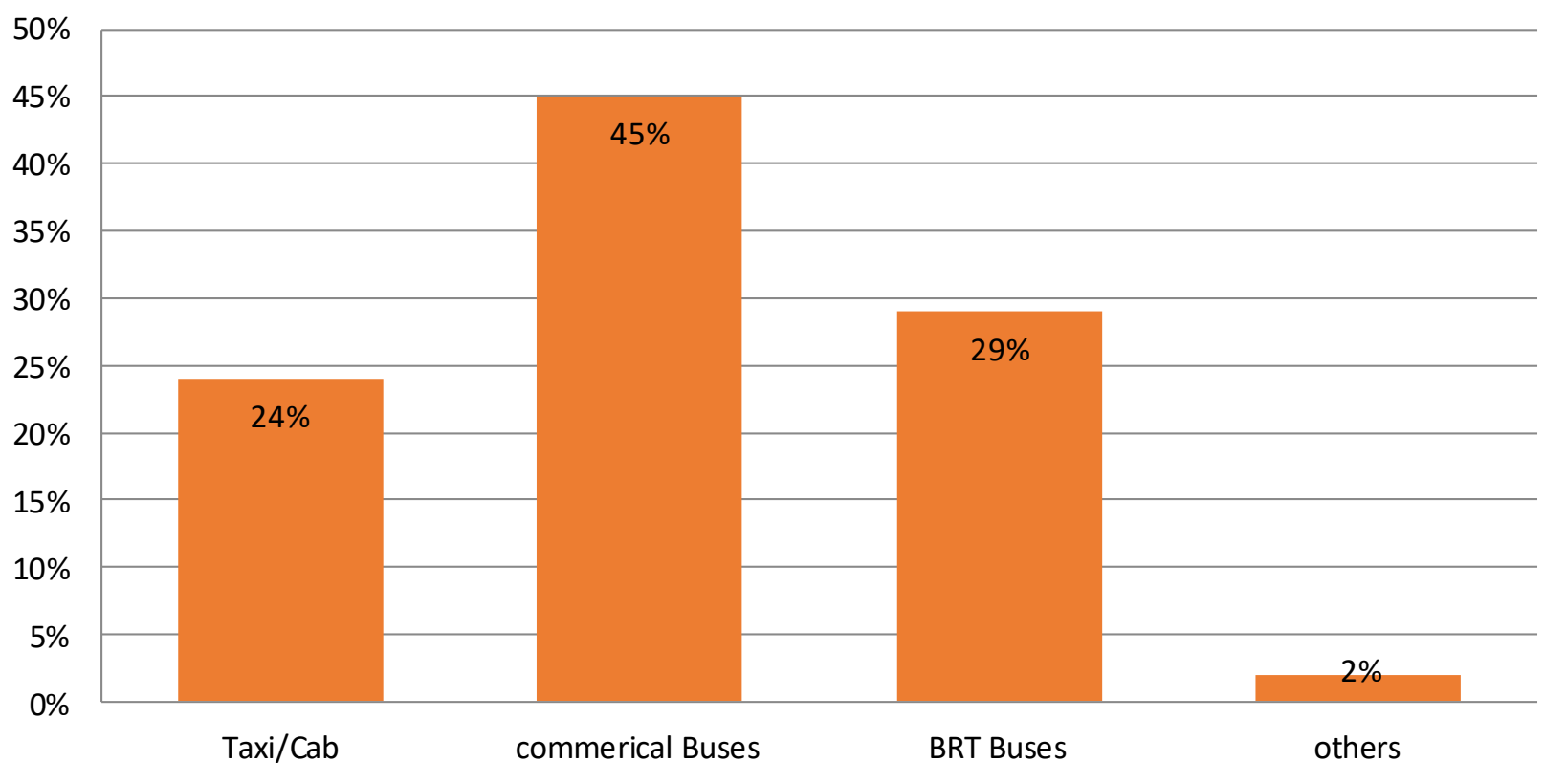

Fig. 2. Means of Commuting

Source: field Survey, 2016. 
The Fig 2 above 4 indicates that 20 respondents representing 24\% use Taxi as means of commuting, 38 respondents representing $45 \%$ use Commercial buses, 24 respondents representing $29 \%$ use BRT buses while 2 respondent representing $2 \%$ use other means of transportation.

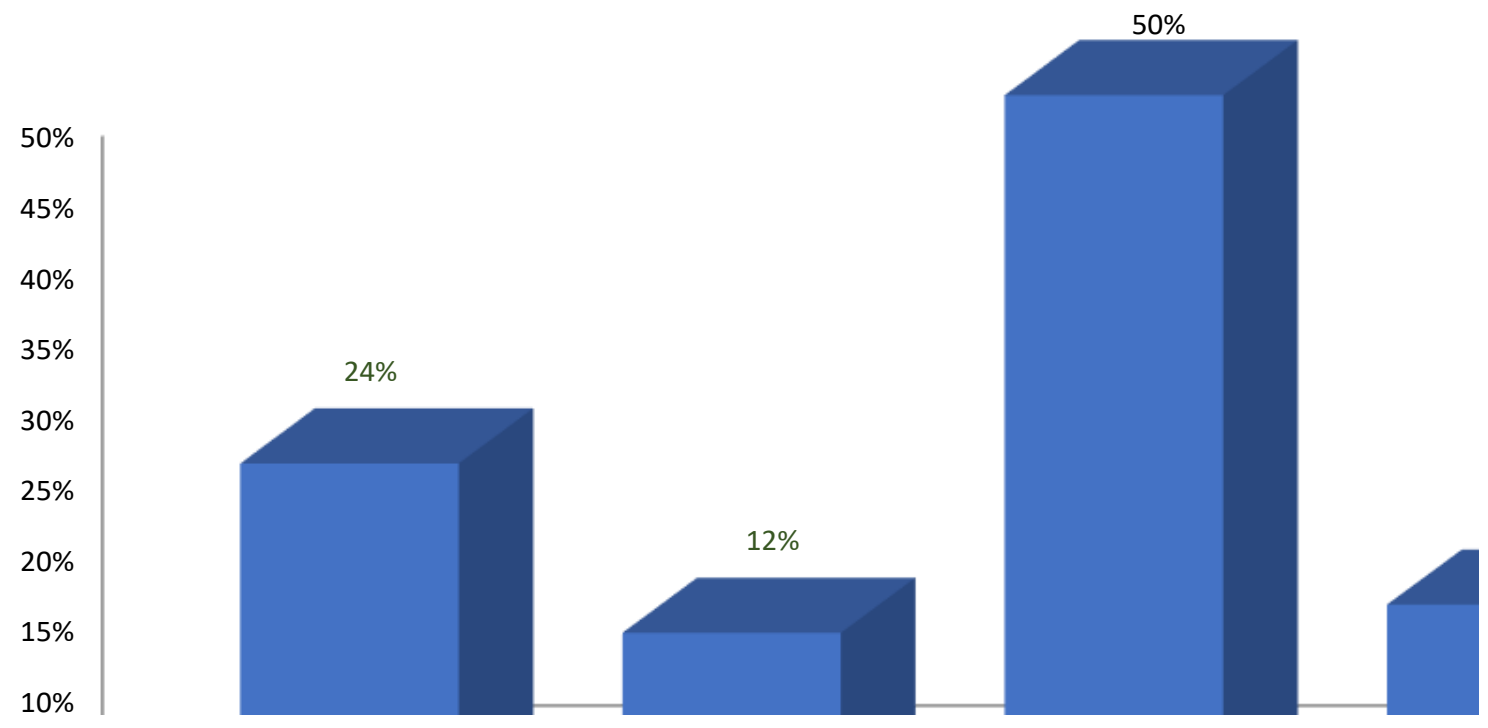

Fig. 3. Vehicle Capacity

Source: field Survey, 2016

The above Fig 3 indicates that 20 respondents representing 24\% use 11 passenger bus, 42 respondent representing 50\% use 32 passenger bus, 12 respondents representing $14 \%$ use others, while 10 respondent representing $12 \%$ use 14 passenger bus.

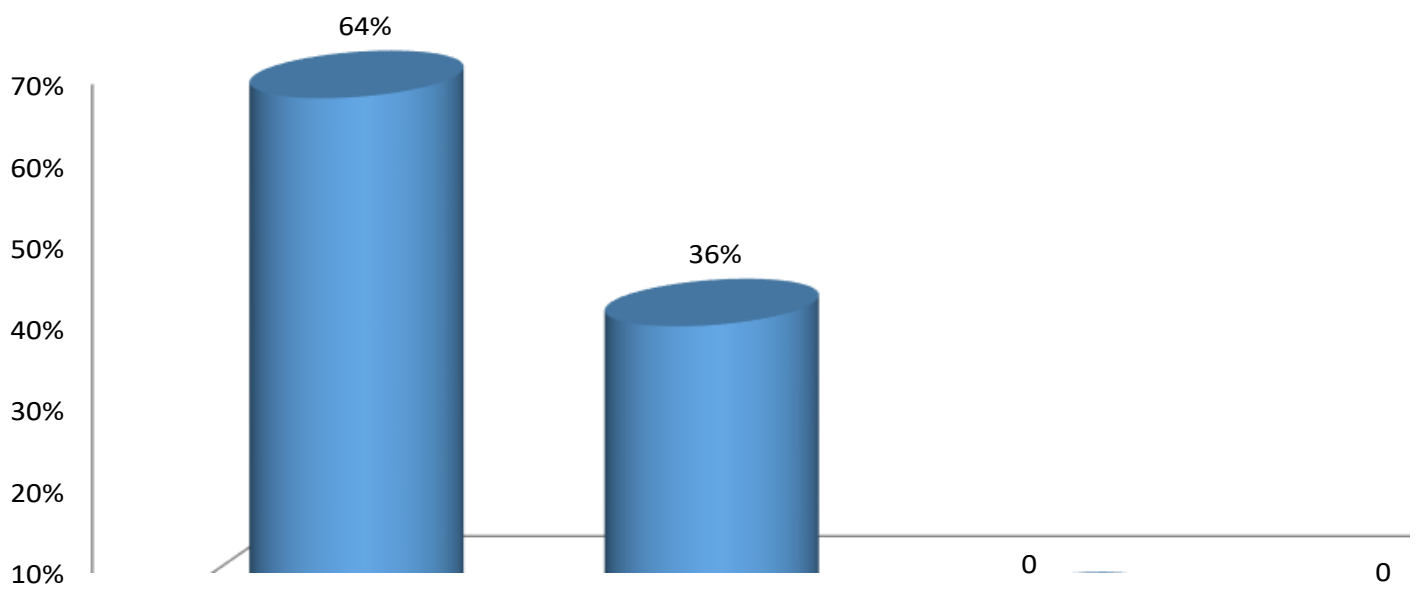

Fig. 4. Frequency of Commuting

Source: field Survey, 2016

The above Fig 4 analysis indicates that 54 respondents representing $64 \%$ commute on daily basis while 30 respondents representing $36 \%$ commute occasionally. 


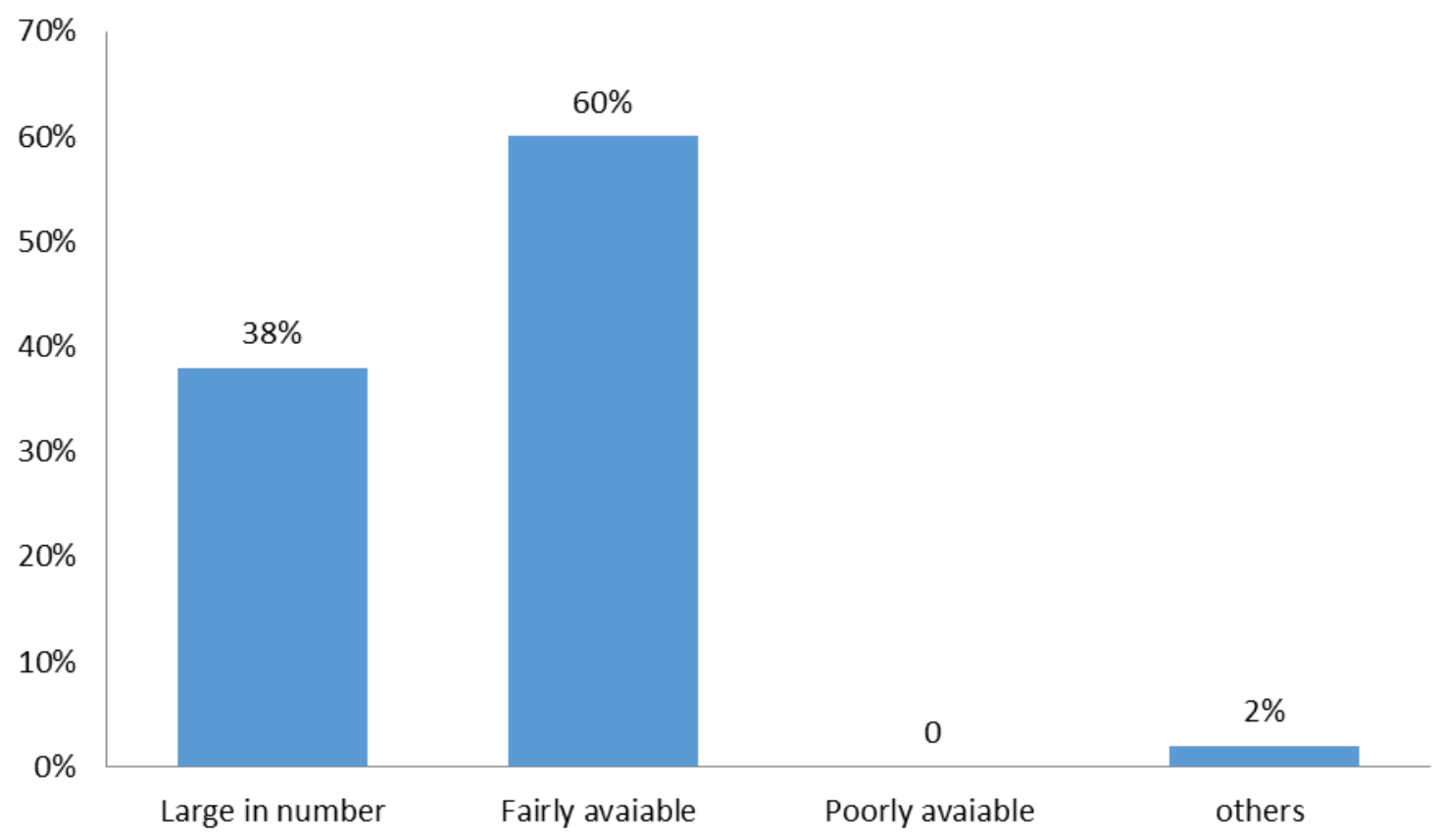

Fig. 5. Adequacy of Commuting Mode

Source: field Survey, 2016.

The Fig 5 analysis above indicates that 32 respondents representing 38\% are large in numbers, 50 respondent representing $60 \%$ Agreed are fairly available, while 2 respondents representing $2 \%$ belongs to others category.

\section{Table 4. Comfort of Means of Commuting}

\begin{tabular}{|l|c|c|c|}
\hline Responses & Code & Frequency & Percentage (\%) \\
\hline Very convenient & $\mathbf{1}$ & $\mathbf{3 6}$ & $\mathbf{4 3}$ \\
\hline Fairly convenient & $\mathbf{2}$ & - & - \\
\hline Highly prone to accident & $\mathbf{3}$ & $\mathbf{4 2}$ & $\mathbf{5 0}$ \\
\hline Others(please specify) & $\mathbf{4}$ & $\mathbf{6}$ & $\mathbf{7}$ \\
\hline Total & & $\mathbf{8 4}$ & $\mathbf{1 0 0}$ \\
\hline
\end{tabular}

Source: field Survey, 2016.

Table 4 results indicate that 36 respondents representing $43 \%$ of the samples, affirmed that they very convenient while commuting, 42 of them representing $50 \%$ of the samples, said they were highly prone to accidents during commuting in the state, while 4 of the respondents representing $7 \%$, agreed that commuting in Lagos State was fairly good. This means that majority of the commuters agreed that commuting in Lagos State, is risky.

\subsubsection{Social Characteristics of Respondents}

Table 5. Sex distribution
\begin{tabular}{|l|c|c|c|}
\hline Sex & Code & Frequency & Percentage (\%) \\
\hline Male & 1 & 48 & 57 \\
\hline Female & 2 & 36 & 43 \\
\hline Total & & $\mathbf{8 4}$ & $\mathbf{1 0 0}$ \\
\hline
\end{tabular}

Source: field Survey, July 2016.

Table 5 results indicate that 48 respondents representing 57\% are male while 36 respondents representing $43 \%$ are female. This means that more male respondents were used in the study. 


Table 6. Occupations of Respondents
\begin{tabular}{|l|c|c|c|}
\hline \multicolumn{1}{|c|}{ Status } & Code & Frequency & Percentage (\%) \\
\hline Self employed & 1 & 8 & 9 \\
\hline Private employment & 2 & 24 & 29 \\
\hline Civil servants & 3 & 52 & 62 \\
\hline Others & 4 & & \\
\hline Total & & $\mathbf{8 4}$ & $\mathbf{1 0 0}$ \\
\hline
\end{tabular}

Source: field Survey, 2016.

Table 6 results indicate that 8 respondents representing 9\% were self-employed, 24 respondents representing $29 \%$ were in private company employments, while 52 respondents representing $62 \%$ were Civil servants. Thus, most of the respondents were Civil servants.

Table 7. Range of Income per Month of Respondents

\begin{tabular}{|l|c|c|c|}
\hline \multicolumn{1}{|c|}{ Range of Income } & Code & Frequency & Percentage(\%) \\
\hline Less than N25,000 & 1 & 22 & 26 \\
\hline N25,000-N45,000 & 2 & 24 & 29 \\
\hline N46,000-N65,000 & 3 & 22 & 26 \\
\hline N66,000-N85,000 & 4 & 12 & 14 \\
\hline N86,000-N105,000 & 5 & 4 & 5 \\
\hline N106,000 and above & 6 & - & - \\
\hline Total & & $\mathbf{8 4}$ & $\mathbf{1 0 0}$ \\
\hline
\end{tabular}

Source: field Survey, 2016.

Table 7 results showed that 22 respondents representing $26 \%$ were within salary range of less than $\mathrm{N} 25,000,24$ respondents representing $29 \%$ were within salary range of N25,000-N45,000, 22 respondent representing 26\% were within N46,000-N65,000, 12 respondents representing 14\% were within N66,000-N85,000, while 4 respondents representing 5\% earned between N86,000-N105,000 as salaries.

\subsection{Testing of Hypotheses}

\section{Research Hypothesis One}

$\mathrm{H}_{0}$ : There is no significant correlation between frequency of travels and commuters' income in Lagos Metropolis.

$\mathrm{H}_{1}$ : There is a significant correlation between frequency of travels and commuters' income in Lagos Metropolis.

Hypothesis one was answered using the Pearson Product Moment Correlation Coefficient tool at 0.05 level of significance to determine the correlation between frequency of travels and commuters' income in Lagos Metropolis. The result is shown in table below:

Table 8. Relationship between Frequency of Travels and Commuters' income in Lagos Metropolis
\begin{tabular}{|l|c|c|c|c|c|c|}
\hline Commuters' Income & $\boldsymbol{X}$ & $\boldsymbol{S D}$ & $\boldsymbol{N}$ & $\boldsymbol{D} \boldsymbol{r}$ & $\boldsymbol{r}$-cal & $\boldsymbol{r}$-crit \\
\hline $\begin{array}{l}\text { Commuters' income - Btw \#25,00 and } \\
\# 65,000\end{array}$ & 34.0 & 12.01 & 68 & & & \\
$\begin{array}{l}\text { Commuters' income Btw \#66,000 and } \\
\# 105,000\end{array}$ & 8.59 & 4.91 & 16 & 82 & 0.608 & 0.195 \\
\hline
\end{tabular}

\section{* Significant at $0.05 ; d f=82$}

Table 11 results showed that the value of r-calculated $(0.608)$ is significantly greater than the value of r-critical (0.195) given 82 degrees of freedom at 0.05 level of significance. This resulted in the rejection of the null hypothesis and the acceptance of the alternative hypothesis which states that there is a significant correlation between frequency of travels and commuters' income in Lagos 
Metropolis, Nigeria. The above responses indicated that a clear correlation exists between frequency of travels and commuters' income in Lagos Metropolis.

\section{Hypothesis Two}

$\mathrm{H}_{0}$ : There is no significant correlation between frequency of travels and distance covered by commuters in Lagos Metropolis.

$\mathrm{H}_{1}$ : $\quad$ There is significant correlation between frequency of travels and distance covered by commuters in Lagos Metropolis.

Research hypothesis two was answered using the Pearson Product Moment Correlation Coefficient Statistical tool at 0.05 level of significance to determine the level of correlation between frequency of travel and distance covered by commuters in Lagos Metropolis. The result is presented in the table below:

Tab. 9: Correlation between Frequency of Travel and Distance Covered by Commuters in Lagos
Metropolis
\begin{tabular}{|l|c|c|c|c|c|c|c|}
\hline Frequency of Travels & $\boldsymbol{X}$ & $\boldsymbol{S D}$ & $\boldsymbol{N}$ & & $\boldsymbol{D} \boldsymbol{f}$ & $\boldsymbol{r}$-cal & $\boldsymbol{r}$-crit \\
\hline On Daily Basis & 26.0 & 12.40 & 54 & & & & \\
& & & & & & & \\
On Occasional Basis & 15.0 & 6.61 & 30 & & 82 & 0.465 & 0.195 \\
\hline
\end{tabular}

* Significant at 0.05; $d f=82$

Table 12 results showed that the value of r-calculated $(0.465)$ is significantly greater than the value of r-critical (0.195) given 82 degrees of freedom at 0.05 level of significance. This led to the rejection of the null hypothesis and the acceptance of the alternative hypothesis that there is a significant correlation between frequency of travels and distance covered by commuters in Lagos Metropolis.

\section{Conclusion}

Based on the results that emerged at the end of the data analyses, it was concluded that there is a correlation between frequency of travels and commuters' incomes in Lagos State, Nigeria and that there is a correlation between frequency of travels and distance covered by commuters in Lagos State, Nigeria. This further indicates that commuters' frequency of travels is determined by their level of income in Lagos State and that there is a correlation between frequency of travels and the distances covered by the commuters in Lagos State, Nigeria.

High increasing motorization in Lagos causes many problems in traffic congestion, a high level of pollution, a high consumption non-renewable energy resource, a threat to quality of life and a high number of traffic accidents. Public bus transport should become the solution for sustainable transport in the future, which is the reason to increase customer satisfaction. High quality public bus transport not only keep customer to continue using public bus transport to fulfill their travel demand but also attract potential customer.

There is need to ensure greater coordination with local planning and operating agencies for the purpose of identifying water potential, the need to conduct research, develop operational techniques and promote the use of technology to enable safe and efficient deployment of public transportation system.

\section{Appendix A. Supplementary material}

Supplementary data associated with this article can be found, in the online version, at http://jsdtl.sciview.net

\section{Funding}

The authors received no direct funding for this research. 


\section{Citation information}

Afolabi, O.J., Hassan, A.M., \& Age, L.O. (2017). Behavioural pattern of commercial public transport passengers in Lagos metropolis. Journal of Sustainable Development of Transport and Logistics, 2(1), 40-50. doi:10.14254/jsdtl.2017.2-1.4

\section{References}

Afolabi, J. O. (2008). Road traffic congestion and its impact on social and Economic Activities in Lagos State. B.Sc. Dissertation, Department of Transportation Planning and Management, Olabisi Onabanjo University, Ago-iwoye, Nigeria.

Afolabi, J. O. (2014). Passenger Satisfaction of Public Bus Transport in Lagos State. M.Sc. Dissertation, Department of Transportation Planning and Management, Olabisi Onabanjo University, Agoiwoye, Nigeria.

Agunloye, 0. 0. (2011). Analysis of the travels of public transport passengers (road) in Ikorodu, Lagos, Nigeria. Journal of Geoography and Regional Planning, 4(7), 443-448.

Badejo, B. A. (2002). The dilemma of emerging urban public transportation in Nigeria. Lasu Journal of Social Science, 4.

Fadare, S. O., \& Ayantoyinbo, B. B. (2010). A study of the effects of road traffic congestion on freight movement in Lagos metropolis. European Journal of Social Sciences, 16(3), 420-429.

Handy, S. (2001). Travel choices in berkley: Automobiles, Accessibility, and the Evolution of road mode. Berkeley Planning Journal, 20(3), 15-33.

Munby, D. L. (Ed.). (1968). Transport: selected readings (Vol. 58). Penguin Books.

Odeleye, J. A. (2001, October). Towards gender sensitive urban transport planning and operations in metropolitan Lagos, Nigeria. In Paper for the 4TH IFUP Congress October, Marrakech, Morocco. Retrieved from http://ww2.unhabitat.org/programmes/ifup/conf/odeleye.pdf.

Ogwude, I. C. (2011). Transport Infrastructure and Mobility in Nigeria. JORIND, 9(1), 456-467.

Olawole, M. O. (2012). Accessibility to Lagos bus rapid transit (BRT LITE) bus stops: an empirical study. In International Conference on the role of urban mobility in (re) shaping cities-CODATU $X V$ (Vol. 22).

Oni, S. S. (2004). Development of Urban Transportation. In Chikolo, I. Ogunsanya, A.A. and Sumaila, A.G. (Eds). Perspectives on Urban Transportation in Nigeria. NITT. Zaria.

Parker, D., Manstead, A. S., \& Stradling, S. G. (1995). Extending the theory of planned behaviour: The role of personal norm. British Journal of Social Psychology, 34(2), 127-138.

Schwebel, D. C., Severson, J., Ball, K. K., \& Rizzo, M. (2006). Individual difference factors in risky driving: The roles of anger/hostility, conscientiousness, and sensation-seeking. Accident Analysis \& Prevention, 38(4), 801-810.

Zeithaml, \& Bitner. (2000) Psychological and social factors influencing motorcycle river intentions and behavior. Australia transport safety Bureau Research and Analysis Report.

Zumkeller, D. (2000). The impact of telecommunication and transport on spatial behaviour. Periodica Polytechnica. Transportation Engineering, 28(1-2), 23-38.

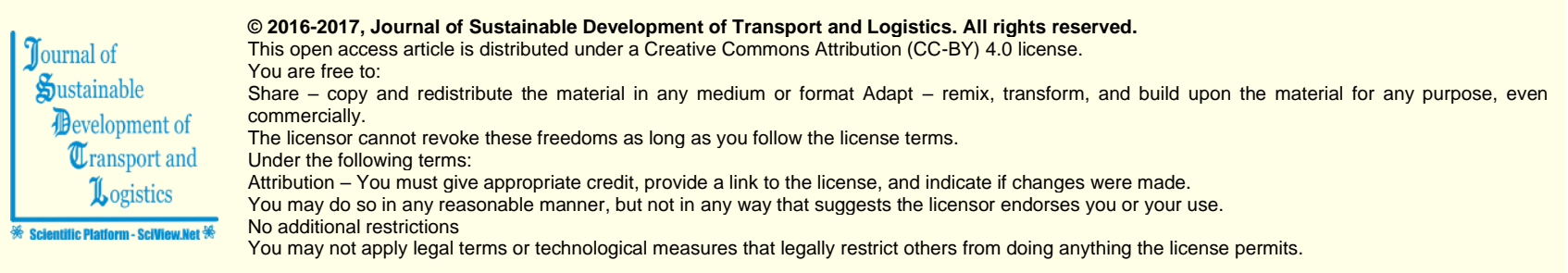

Journal of Sustainable Development of Transport and Logistics (ISSN: 2520-2979) is published by Scientific Publishing House "CSR", Poland, EU and Scientific Publishing House "SciView", Poland, EU

Publishing with JSDTL ensures:

- Immediate, universal access to your article on publication

- Immediate, universal access to your article on publication

- Rapid publication

- Ruaranteed legacy preservation of your article

- Discounts and waivers for authors in developing regions

Submit your manuscript to a JSDTL at http://jsdtl.sciview.net/ or submit.jsdt|@sciview.net 